\title{
Leveraging the Annual Wellness Visit to Improve Rural Depression Management
}

\author{
Emily Sundeen, DNP, FNP-BC ${ }^{1}$ \\ Warseal Powell, DNP, FNP-BC ${ }^{2}$ \\ Robert Deuell, $\mathrm{MD}^{3}$
}

${ }^{1}$ Family Nurse Practitioner, Hunt Memorial Hospital District and Hunt Regional Medical

Partners, esundeen@huntregional.org

${ }^{2}$ Assistant Professor, Community Mental Health, University of South Alabama College of

Nursing, warsealpowell@,southalabama.edu

${ }^{3}$ Medical Director, Hunt Regional Medical Partners, rdeuell@huntregional.org

\begin{abstract}
Purpose: Depression is a common condition in rural primary care associated with significant adverse health and quality of life outcomes. Despite evidence-based practice recommendations, depression screening and follow-up are inconsistent in practice. The purpose of this quality improvement project was to improve the rate of depression screening and management as a component of the Annual Wellness Visit (AWV) in the rural, primary care setting. The overarching project aim was to increase the rate of depression screening and treatment in adult Medicare patients by $50 \%$ through the implementation of a standardized screening instrument and management plan within eight weeks of project implementation.
\end{abstract}

Sample: The sample population included 66 Medicare beneficiaries receiving a Medicare Annual Wellness Visit at a primary care practice in rural Northeast Texas.

Method: The central focus of this quality improvement project was to initiate standardized depression screening and management in the Medicare population as a component of the annual Online Journal of Rural Nursing and Health Care, 20(1) http://dx.doi.org/10.14574/ojrnhc.v20i1.602 
wellness visit. Patients were screened for depression using the Patient Health Questionnaire-9 (PHQ-9) instrument. An evidence-based depression management plan based on the PHQ-9 score guided follow-up and management.

Findings: When depression screening was performed as a component of the AWV, $98.5 \%$ of patients received depression screening with a validated instrument. $73.3 \%$ of patients who had a PHQ-9 score of five or greater had a documented follow-up plan, and $93.3 \%$ had recommended treatment initiated. A strong positive correlation was found among patients who screened positive for depression and received a documented follow-up plan (rho $(63)=.993, \mathrm{p}<.001)$ and had treatment plan initiated (rho $(63)=.998, \mathrm{p}<.001)$.

Conclusions: Implementing standardized workflows, such as the annual wellness visit, is foundational to consistently identify and treat depression to remission in the rural primary care setting.

Keywords: depression, screening, preventive services, Patient Health Questionnaire-9, annual wellness visit.

\section{Leveraging the Annual Wellness Visit to Improve Rural Depression Management}

Major depressive disorder (MDD) is the most prevalent psychiatric illness in the United States (U.S.) (Akincigil \& Matthews, 2017). According to the American Psychiatric Association (APA) (2013), hallmark features of depression persisting for longer than two weeks include a depressed mood, hopelessness, and loss of interest in usual activities. Depression is an incapacitating illness linked with multiple adverse outcomes, including higher rates of self-harm, morbidity, mortality, and the inability to manage self-care (Kim et al., 2015). Depression is often 
a confounding condition in individuals with other chronic diseases and has a substantial impact on the individual's overall physical health and quality of life (Pruchno et al., 2016). Only half of individuals in the primary care setting with depression receive treatment and follow-up despite effective treatment options (Picardi et al., 2016).

To improve depression screening and management in the primary care setting, a quality improvement (QI) project was developed to incorporate depression screening and management as a component of the Medicare annual wellness visit (AWV). The central focus of this improvement project was to initiate standardized depression screening in the Medicare population during the AWV to improve rates of depression screening and treatment. The specific aims of the project were to (1) educate clinical staff on depression screening and management, (2) perform the Patient Health Questionnaire-9 (PHQ-9) (Patient Health Questionnaire Screeners, 1999) depression screening as a component of the AWV, and (3) initiate an evidence-based depression management plan with patients who screen positive for depression. A directed practice question was developed to address the identified problem as: Will the implementation of a standardized depression tool in adult Medicare patients at an AWV improve early identification and treatment of depression in eight weeks?

\section{Depression Related Disparities}

\section{Depression in the United States and Texas}

Depression is a chronic condition impacting approximately one in ten individuals in the United States (Akincigil \& Matthews, 2017). The prevalence of depression increases with advancing age and co-occurring chronic conditions, with approximately $25 \%$ of adults over the age of 60 experiencing depression (Pruchno et al., 2016). National and state aggregate data on the 
scope of depression and mental health disparities illustrate an urgent need for improvement. According to the National Alliance on Mental Health (2018), approximately 7\% of Americans live with major depressive disorder. Texas ranks $39^{\text {th }}$ out of 50 states in mental illness prevalence and 49th in access to mental healthcare (Mental Health America [MHA], 2018). Most worrisome, Texas ranks first in states with the highest prevalence of adults with serious thoughts of suicide (MHA, 2018).

\section{Depression in Hunt County}

Local and practice site-specific data analysis also supports the need for rapid improvement. Hunt County is classified as a health professional shortage area and a medically underserved area (U.S. Department of Health and Human Services, 2018a and 2018b). According to the University of Wisconsin Population Health Institute (UWPHI) (2018), Hunt County is significantly below the Texas average in healthcare providers. The Hunt County ratio of patients to primary care physicians is 3,100:1 versus the Texas average of 1,670:1 (UWPHI, 2018). The Hunt County ratio of patients to mental health providers is 1,560:1 compared to the state average of 1,010:1 (UWPHI, 2018). Additionally, rates of depression in the Medicare population in Hunt County is $21.5 \%$, significantly higher than the state average of $17 \%$ and the U.S. average of $16.7 \%$ (Dallas Fort Worth Hospital Council Foundation, 2018). Site-specific data obtained from electronic health record data reflects that in 2018, the practice site provided primary care for 6,176 unique patients. Of those, $14 \%$ of the patient population had an ICD-10 code for depression on their active problem list. The payor mix at the practice setting is $26 \%$ traditional Medicare, resulting in 1,605 Medicare beneficiaries eligible for an AWV. 


\section{Defining the Rural Population}

Approximately 60 million Americans or 17\% of the country's population live in a rural area (Bolin et al., 2015). The definition of a rural is multidimensional and complex. According to the U.S. Census Bureau, rural is "what is not urban" (Ratcliffe et al., 2016). Factors used to classify rural locations include population thresholds, population density, land use, and distance to urban development. More specifically, rural is defined as a geographic area with 50,000 or fewer people and a population density of fewer than 1,000 people per square mile (Ratcliffe et al., 2016).

According to the National Rural Health Association (2019), rural communities experience significant obstacles to healthcare, including social isolation, poverty, and geographic factors. Rural populations also experience healthcare disparities related to the lack of access to mental health providers (Mental Health America, 2018). Rural Healthy People 2020 have identified the highest priority health challenges in rural America include (1) access to healthcare, (2) nutrition/obesity, (3) diabetes, (4) mental health disorders, and (5) substance abuse (Bolin et al., 2015).

The practice setting of the QI project is located in Hunt County, which is designated as urban in the Dallas-Fort Worth metropolitan area (Texas Department of Agriculture, 2016). Four rural counties border Hunt County, none of which have a hospital. As a regionally integrated health system, the system provides care to the population in the four bordering rural counties. The primary care division includes five clinics located throughout Hunt County. Two of the clinics are certified Rural Health Centers to provide healthcare for the rural and medically underserved population (Medicare Learning Network, 2018). The operational definition of rural for this QI project is a healthcare organization serving a rural population. 


\section{Review of the Literature}

\section{U.S. Preventive Services Task Force Recommendations}

The U.S. Preventive Services Task Force (USPSTF) was formed in 1984 as an expert, volunteer panel to develop evidence-based recommendations regarding preventive health interventions (U.S. Preventive Services Task Force, 2019). The mission of the USPSTF is to standardize and disseminate evidence-based preventive services to improve the overall health of the population (Kurth et al., 2018). Despite extensive dissemination efforts, variations in clinical practice and implementation gaps remain. Currently, Americans receive only approximately half of the recommended preventive health services, illustrating a significant variation in evidencebased care (Kurth et al., 2018).

\section{The Annual Wellness Visit}

Over the past decade, the value of an annual physical exam in asymptomatic adults has been called into question. According to Gorbenko et al. (2017), multiple professional organizations and payors alike note that an annual physical exam leads to unnecessary diagnostic studies with no associated reduction in morbidity. Proponents of an annual preventive visit argue that personalized encounters targeting age and health-status appropriate interventions are associated with improved health outcomes and adherence with recommended preventive services (Gorbenko et al., 2017).

In response, the Centers for Medicare and Medicaid Services (Centers for Medicare and Medicaid Services [CMS], 2018b), has introduced the AWV as a preventative service encounter dedicated to preventive services covered at $100 \%$ by Medicare. To date, there is little research regarding the effectiveness of the AWV to improve adherence with USPSTF recommended 
preventive services. A recent retrospective, observational study concluded that patients who receive an AWV were $62 \%$ more likely than non-recipients to receive recommended cancer screenings (Camacho et al., 2017). Notably, the study also demonstrated that AWVs improved disparities in preventive services in low-socioeconomic and rural populations.

\section{Depression Screening and Management Best Practices}

A review of the literature revealed evidence-based strategies to improve depression identification and management in the primary care setting including (1) educating and training clinical staff regarding depression, administering the Patient Health Questionnaire-9 (PHQ-9) screening, and initiating the depression management plan; (2) standardized depression screening; (3) utilizing a validated instrument to identify clinical depression; and (4) integrating depression screening into the electronic health record (EHR). There is widespread, expert consensus in the literature supporting routine depression screening and subsequent ongoing management in the adult, primary care population (American Psychiatric Association [APA], 2010; Trangle et al., 2016; USPSTF, 2019). Research also supports standardized, routine depression screening utilizing a validated instrument to identify clinical depression in the primary care setting (APA, 2010; Picardi et al., 2016; USPSTF, 2019). EHR optimization by embedding depression screening into the EHR workflow is associated with improved depression screening consistency (Aleem et al., 2015; Bajracharya et al., 2016; Trangle et al., 2016).

The objective of the Institute for Clinical Systems Improvement (ICSI) Health Care Guideline: Depression in Primary Care is to guide primary care providers in designing systems and processes to detect, treat, and manage depression (Trangle et al., 2016). The guidelines focus recommendations on patient-centered care, collaborative multidisciplinary care, care coordination, 
and ongoing outcome evaluation. Guideline recommendations include: (1) routinely screening all adults for depression using a standardized instrument; (2) pharmacologic, psychotherapy, and behavioral interventions; (3) arranging treatment and follow-up; and (4) incorporating shared decision-making with the patient. The guidelines also include a depression management plan based on the severity of depression as determined by the APA diagnostic depression criteria and the PHQ-9 score (Trangle et al., 2016).

\section{Framework}

\section{Quality Improvement Model}

The Model for Improvement methodology incorporating plan, do, study, and act (PDSA) cycles was used as a guide to direct project interventions and accelerated improvement (Langley et al., 2009). The first phase, planning, entailed stakeholder engagement to define the practice problem, collecting baseline depression screening and follow-up rates, and developing objectives and associated interventions. The do phase included clinician education, EHR optimization, depression screening utilizing the PHQ-9, and initiation of the depression management plan. The next study aspect of the cycle encompassed analyzing outcomes and evaluating if the change resulted in the desired state. The final step of the cycle, act, included ongoing evaluation, continued implementation at the pilot clinic, and planning implementation at all system primary care practice sites.

\section{Evidence-Based Practice Model}

Evidence-based practice (EBP) models provide a framework to translate research into practice (Polit \& Beck, 2017). According to Schaffer et al., (2013), the Johns Hopkins Nursing EvidenceBased Nursing (JHNEBP) model is beneficial in providing structure to translate best practices into care delivery. The JHNEBP model (2017) is formed around the acronym PET, representing the model 
processes: practice question, evidence, and translation. The depression practice question was fully developed by establishing the population, intervention, comparison, and outcomes (PICO). Evidence processes included critically appraising the evidence and then designing interventions from evidencebased best practices. Evidence translation occurred through project implementation to ultimately improve depression-related health outcomes.

\section{Theoretical Underpinnings}

The Neuman Systems Model (NSM) (Neuman Systems Model, Inc., 2005) is a theoretical framework focused on the individual's relationship with the environment, stressors, lines of defense, and establishing stability. The NSM is especially applicable in mental health because the individual is conceptualized as a unique, dynamic individual responding to internal and external factors to establish and maintain balance (Whetsell et al., 2015). The NSM is a useful framework to guide wellness interventions concerning prevention (Fawcett \& Foust, 2017). Primary prevention relates to strengthening the lines of defense and reducing the impact of stressors. Secondary prevention encompasses screening for depression. Tertiary prevention involves treating depression to obtain remission and the return of optimal wellness.

\section{Project Purpose}

The purpose of this QI project was to improve the rate of depression screening and subsequent management as a component of the AWV in the primary care setting. The project aim was to increase the rate of depression screening and treatment in adult Medicare patients by $50 \%$ through the implementation of a standardized screening instrument within eight weeks of project implementation. 


\section{Project Design and Methodology}

\section{Ethical Considerations}

According to the USPSTF (2016), routine depression screening is associated with small to no potential for patient harm. No permission is required to reproduce or utilize the PHQ-9 depression screening instrument (Patient Health Questionnaire (PHQ) Screeners, 1999). Prior to implementation, the student researcher received exempt review approval from the University of South Alabama Institutional Review Board (Assurance number FWA 00001602, IRB Database \#00000286, Project \#1423485-1).

\section{Participants}

The sample population for the project was a convenience sample of readily available patients at the pilot primary care practice site who received an AWV. Participant inclusion criteria included patients who received an AWV, were older than age 18, and were Medicare beneficiaries. Exclusion criteria were any patient who declined the AWV or was not a Medicare beneficiary.

\section{Setting}

The practice setting was a primary care clinic owned and operated by an integrated health hospital system. The health system includes a regional hospital, five primary care clinics, and multiple specialty clinics in rural Northeast Texas. The system is in the second year of joining a larger, national Accountable Care Organization (ACO). The ACO is participating in the Medicare Shared Savings Program to improve the quality of healthcare delivery, facilitate population health, and decrease healthcare expenditures (CMS, 2018c). The primary care practice sites have implemented AWVs as a targeted method to improve health promotion and quality outcomes. The QI project was piloted at the largest primary care site for system-wide implementation. Clinical 
staff at the pilot clinic include two family practice physicians, two nurse practitioners, one physician assistant, four medical assistants, and one population health nurse.

\section{Instrument}

The QI project utilized the PHQ-9 instrument to assess and monitor depression. The PHQ9 is a patient-reported, psychosocial instrument developed to detect the diagnostic symptoms of depression (Spitzer et al., 1999). The PHQ-9 questionnaire consists of nine questions measuring the presence, severity, and frequency of depressive symptoms. The PHQ-9 can be used for both detecting and monitoring depression severity facilitating consistent and reliable monitoring (Kroenke et al., 2001).

There is compelling support for utilizing the PHQ-9 for depression screening and management by practice guidelines (APA, 2010; Trangle et al., 2016; USPSTF, 2016). Endorsement of the PHQ-9 is primarily due to the instruments reliably reflecting consistency and validity indicating accuracy. According to the instrument's developers, the PHQ-9 internal reliability was calculated at 0.89 using Cronbach's alpha coefficient (Kroenke et al., 2001). The PHQ-9 diagnostic validity was evaluated by meta-analysis; it demonstrated a pooled sensitivity of 0.76 and a pooled specificity of 0.92 (Moriarty et al., 2015).

\section{Operational Design and Interventions}

Using the PDSA methodology, project planning included collaborating with key stakeholders to identify gaps in current practice and gain the support of the change. A gap analysis was then undertaken to differentiate the current state of depression screening and management from the desired future state. A comprehensive review of the literature regarding depression 
screening and management was then undertaken to design the interventions utilizing evidencebased best practices.

The operational do phase of the improvement cycle entailed implementing project interventions. Preparatory interventions that occurred before implementation included staff education and EHR optimization. Education was targeted towards clinical staff regarding depression, administering the PHQ-9 screening, and initiating the depression management plan. Education was conducted by the advanced practice nurse researcher utilizing the Montana Geriatric Education Center's Screening for Depression in Older Adults module (2014). Knowledge was evaluated with a pretest and posttest. EHR optimization entailed collaborating with the onsite population health nurse (who is also an EHR administrator) to embed the PHQ-9 screening and depression management plan directly into the EHR. The Institute for Clinical Systems Improvement (ICSI) Health Care Guideline: Depression in Primary Care depression treatment plan components of (1) pharmacologic, (2) psychotherapy, and (3) behavioral interventions were embedded into the EHR as discrete fields with corresponding orders and referrals.

Care delivery interventions included: (1) performing standardized depression screening utilizing the PHQ-9 instrument as a component of the AWV; and (2) initiating the ICSI depression treatment plan based on the PHQ-9 score where indicated. Patients were scheduled for an AWV by clinic staff if an AWV encounter had not been provided in the previous 12 months. Patients were asked to present to the clinic 30 minutes before their appointment time to complete medical history update forms. The office staff provided the history update forms, including the PHQ-9 instrument to the patient to be completed in the waiting room. The medical assistant then roomed the patient, reviewed the PHQ-9 assessment findings with the patient, and entered the PHQ-9 score 
into the EHR intake section. Patients with a PHQ-9 score of five or greater were then further evaluated by the primary care provider for clinical depression by assessing risk factors, history, the potential for self-harm, and diagnostic criteria. Complex decision points were derived from the severity of depression and terminate with treatment and establishing a follow-up plan.

\section{Data Analysis}

The study phase of the improvement cycle included evaluation of the QI project objectives and associated quality performance measures. Quality measures included structural measures reflecting evaluating capacity, process measures evaluating method steps, and outcome metrics indicating the effect of the intervention (Donabedian, 2005). Structural measures included the presence of the PHQ9 score and depression management plan embedded in the EHR. Process measures included depression screening as a component of the AWV, expressed as a percentile rate. The numerator was patients screened for depression with the PHQ-9 instrument, and the denominator was all patients receiving an AWV. Adherence with depression management recommendations was measured as a percentile rate where the numerator was patients who score five or greater on the PHQ-9 who have a management plan initiated and follow-up arranged, and the denominator was all patients with a PHQ9 score of five or greater. An outcome-based performance measure was selected to evaluate learner knowledge following project education with a pretest and posttest.

The QI project included methods to ensure data accuracy to safeguard the integrity of findings. Electronic health record documentation facilitated data collection by enabling EHR-generated reports to capture discrete data points, including the PHQ-9 score, a documented follow-up plan, and treatment. A data abstraction tool was utilized to ensure complete information was collected from the EHR. Statistical analysis was performed using IBM SPSS version 24 software to compute and 
transform the data into interpretive findings (Cronk, 2018). Descriptive statistics, including frequency distribution and measurements of central tendency, was calculated to summarize ordinal data. A correlational analysis was then performed to identify the strength of the association between patients who had a positive depression screening and received a documented plan for follow-up and had the depression treatment plan initiated.

\section{Results}

The first project objective was to educate and train clinical staff regarding depression, administering the PHQ-9 screening, and initiating the depression management plan as demonstrated by posttest score of $80 \%$ or greater within two weeks of project implementation. Clinical staff education was conducted utilizing the Montana Geriatric Education Center's Screening for Depression in Older Adults module (2014). Knowledge was evaluated with a pretest and posttest within the module content regarding depression, administering the PHQ-9 screening, and initiating the depression management plan. An outcome-based performance measure was selected to evaluate learner knowledge following project education with a pretest and posttest. The sample size included nine clinicians. A paired-samples $t$-test was calculated to compare the mean pretest and posttest. The mean pretest score was $58.89(\mathrm{SD}=18.33)$, and the mean posttest score was $93.33(\mathrm{SD}=8.66)$. A significant increase in scores from the pretest and posttest was found $(t(8)$ $=-7.750, \mathrm{p}<.001)$.

The second project objective was to perform the PHQ-9 depression screening assessment in $80 \%$ of Medicare patients in primary care receiving an AWV within eight weeks of project implementation. Process performance measures included depression screening as a component of the AWV, expressed as a percentile rate. The numerator was patients screened for depression with the 
PHQ-9 instrument, and the denominator was all patients receiving an AWV. The sample size included 66 Medicare beneficiaries who received an AWV during the eight-week implementation period. The sample population gender distribution was $54.5 \%$ female and $45.5 \%$ male. The participant mean age was $73.77(\mathrm{SD}=8.927)$. The median age was 72 , with a range of 58 years. Of the 66 participants who received an AWV, 65 participants (98.5\%) received depression screening using the PHQ-9 tool. The mean PHQ-9 score was $2.86(\mathrm{SD}=3.665)$, and the median was 2.0 with a range of 15 points.

The third project objective was to initiate the depression treatment plan in $50 \%$ of patients receiving an AWV who screen positive for depression as indicated by a PHQ-9 score of five or greater within eight weeks of project implementation. A PHQ-9 score of five or greater was considered a positive screening indicating potential depression. Of the patients receiving a PHQ9 screening, 15 patients (23.1\%) had a positive screening. Crosstabulation analysis was performed to determine the rate of patients who screened positive for depression and received the recommended treatment. Eleven (73.3\%) of the 15 patients who had a PHQ-9 score of five or greater had a documented follow-up plan, and $14(93.3 \%)$ had recommended treatment initiated. A Spearman rho correlation coefficient was calculated to determine the presence of a relationship between a PHQ-9 of five or greater and documented follow-up and treatment plan initiated. A strong positive correlation was found with a documented follow-up plan $\left(r_{s}(63)=.993, \mathrm{p}<.001\right)$ and treatment plan initiated $\left(r_{s}(63)=.998, \mathrm{p}<.001\right)$, indicating a significant relationship between the variables. Patients with a positive depression screening as a component of the AWV tended to receive documented plans for follow-up and have a treatment plan initiated. Crosstabulation analysis was used to determine the type of depression treatment initiated. Of the 15 patients with 
a positive PHQ-9 screening, 83\% received brief counseling, 13.33\% received pharmacotherapy, and $6.67 \%$ received no treatment.

\section{Summary}

The overarching aim of the QI project was to increase the rate of depression screening and treatment in adult Medicare patients by $50 \%$ through the implementation of a standardized screening instrument within eight weeks of project implementation. Performing depression screening and management as a component of the AWV was a new process at the practice; therefore, there was no true baseline comparison. To evaluate overall project effectiveness, the 2018 Merit-based Incentive Program (MIPS) performance on ACO-18: Prevention Care and Screening for Clinical Depression and Follow-up Plan was used as a comparison (CMS, 2018a). In 2018, 34.29\% of patients at the practice site received depression screening and a documented follow-up plan. When depression screening and management was performed as a component of the AWV, 98.5\% of patients received depression screening, $73.3 \%$ of patients with a positive depression screening received a plan for follow-up, and $93.3 \%$ of patients with a positive depression screening received recommended treatment exceeding the project aim. 
Table 1

Summary of Findings

\section{Summary of Findings}

Aim: Increase the rate of depression screening and treatment in adult Medicare patients by $50 \%$ through the implementation of a standardized screening instrument within eight weeks of project implementation.

\begin{tabular}{|c|c|c|c|c|}
\hline $\begin{array}{c}\text { Associated } \\
\text { Interventions }\end{array}$ & $\begin{array}{c}\text { Performance } \\
\text { Measure }\end{array}$ & Goal & Findings & Achievement \\
\hline $\begin{array}{l}\text { Educate clinical } \\
\text { staff on depression } \\
\text { screening and } \\
\text { management and } \\
\text { evaluate with a } \\
\text { pretest and posttest. }\end{array}$ & Outcome & $\begin{array}{l}\text { Greater } \\
\text { than } 80 \%\end{array}$ & $\begin{array}{l}\text { Paired-samples t-test } \\
\text { mean pretest score } \\
58.89(\mathrm{SD}=18.33) \\
\text { mean posttest score } \\
93.33(\mathrm{SD}=8.66)\end{array}$ & $\begin{array}{l}\text { Met } \\
\text { A significant increase in } \\
\text { scores from the pretest } \\
\text { and posttest was found }(t \\
(8)=-7.750, p<.001)\end{array}$ \\
\hline
\end{tabular}

Objective 2: Perform the Health Questionnaire 9 (PHQ9) depression screening

\begin{tabular}{|c|c|c|c|c|}
\hline $\begin{array}{c}\text { Associated } \\
\text { Interventions }\end{array}$ & $\begin{array}{c}\text { Performance } \\
\text { Measures }\end{array}$ & Goal & Findings & Achievement \\
\hline $\begin{array}{l}\text { Embed the PHQ-9 } \\
\text { screening into the } \\
\text { Electronic Health } \\
\text { Record }\end{array}$ & Structural & Present & Completed & Met \\
\hline $\begin{array}{l}\text { Perform depression } \\
\text { screening using the } \\
\text { PHQ-9 tool as a } \\
\text { component of the } \\
\text { AWV. }\end{array}$ & Process & $\begin{array}{l}\text { Greater } \\
\text { than } 80 \%\end{array}$ & $\begin{array}{l}98.5 \%(\mathrm{n}=65) \text { The } \\
\text { mean PHQ-9 score } \\
\text { was } 2.86(\mathrm{SD}= \\
3.665) \text {, the median } \\
\text { was } 2.0 \text { with a range } \\
\text { of } 15 \text { points }\end{array}$ & Met \\
\hline \multicolumn{5}{|c|}{ Objective 3: Initiate an evidenced-based plan with patients who screen positive for depressior } \\
\hline $\begin{array}{c}\text { Associated } \\
\text { Interventions }\end{array}$ & $\begin{array}{c}\text { Performance } \\
\text { Measures }\end{array}$ & Goal & Findings & Achievement \\
\hline $\begin{array}{l}\text { Embed the } \\
\text { depression } \\
\text { management plan } \\
\text { into the Electronic } \\
\text { Health Record }\end{array}$ & Structural & Present & Completed & Met \\
\hline
\end{tabular}

Online Journal of Rural Nursing and Health Care, 20(1)

http://dx.doi.org/10.14574/ojrnhc.v20i1.602 


\begin{tabular}{|l|l|l|l|l|}
\hline $\begin{array}{l}\text { Initiate the } \\
\text { depression } \\
\text { management plan in } \\
\text { patients who have a } \\
\text { positive PHQ-9 } \\
\text { score of 5 or greater }\end{array}$ & Process & $\begin{array}{l}\text { Greater } \\
\text { than 50\% }\end{array}$ & $\begin{array}{l}\text { Follow-up plan: } \\
73.3 \%(\mathrm{n}=15) \\
\text { Recommended } \\
\text { treatment initiated: }\end{array}$ & $\begin{array}{l}\text { Met } \\
\text { Significant Spearman rho } \\
\text { correlation coefficient }\end{array}$ \\
& & $93.3 \%$ & $\begin{array}{l}\text { PHQ-9 of 5 or greater and } \\
\text { follow-up plan }\left(r_{s}(63)=\right. \\
\end{array}$ & \\
& & & $\begin{array}{l}993, \mathrm{p}<.001) \\
\text { PHQ-9 of 5 or greater and } \\
\text { treatment plan initiated }\left(r_{s}\right. \\
(63)=.998, \mathrm{p}<.001)\end{array}$ \\
\hline
\end{tabular}

\section{Limitations}

The project study design included convenience sampling to boost participant accessibility. Utilization of convenience sampling may create potential bias, thereby reducing the generalizability of findings (Polit \& Beck, 2017). The relatively small sample size and narrow geographic location were also project limitations that may limit the generalizability of the findings.

\section{Practice Implications}

Qualitative research has demonstrated that healthcare consumers have an overall low-level knowledge of recommended preventive services; however, they have a strong preference for shared decision-making regarding preventive services (Lantz et al., 2016). The AWV is a dedicated platform to educate patients on preventive services so they can make informed decisions regarding their care. Research has also demonstrated that simple, low-cost interventions, such as email reminders, formal education, individual performance feedback, and environmental prompts, when used together are effective at improving guideline adherence (Egger et al., 2017).

According to Mabry-Hernandez et al. (2018), implementation and translational research is needed to identify effective processes and workflows to facilitate adherence with USPSTF recommendations in primary care. Healthcare system barriers related to adherence gaps include the volume of primary care recommendations, time constraints, clinician familiarity with current 
recommendations, and the lack of structured workflows to address preventive services (MabryHernandez et al., 2018). As of 2015, approximately $60 \%$ of primary care providers are employed by healthcare systems (American Academy of Family Physicians, 2015). Healthcare systemrelated strategies that promote guideline adherence include multilevel review processes, extensive use of health information technology that incorporate electronic templates and prompts, widespread communication, performance-based financial incentives, individual, real-time feedback, and most importantly provider engagement (Doherty et al., 2018).

Primary care providers are uniquely and favorably positioned to detect, diagnose, and manage depression. Innovative solutions are needed in the rural population to reduce variation in clinical practice related to depression diagnosis and treatment. Incorporating depression screening and management as a component of the AWV in the primary care setting is an intervention that will improve access to mental healthcare in rural communities. Implementing depression screening and follow-up in tandem with the AWV is a structured method to translate evidence into improved outcomes. Routine depression screening is not a new intervention; however, utilizing the AWV to deliver screening in a more consistent manner is an innovative approach.

\section{Conclusion}

Depression is a debilitating, chronic illness, which negatively impacts both mental and physical health. Depression is a common condition in the primary care setting that often goes undetected. Interventions are needed to improve access to healthcare and mental health disparities in the rural population. Implementing standardized workflows in the primary care setting, such as the AWV, is foundational to consistently identify and treat depression toward remission. 


\section{References}

Akincigil, A., \& Matthews, E. B. (2017). National rates and patterns of depression screening in primary care: Results from 2012 and 2013. Psychiatric Services, 68(7), 660666. https://doi.org/10.1176/appi.ps.201600096

Aleem, S., Torrey, W. C., Duncan, M. S., Hort, S. J., \& Mecchella, J. N. (2015). Depression screening optimization in an academic rural setting. International Journal of Health Care Quality Assurance, 28(7), 709-725. https://doi.org/10.1108/IJHCQA-01-2015-0012

American Academy of Family Physicians. (2015). The physician employment trend: What you need to know. Retrieved from https://www.aafp.org/fpm/2015/0700/p11.html

American Psychiatric Association. (2013). Depressive Disorders. In Diagnostic and Statistical Manual of Mental Disorders (5 ed.). Arlington, VA: American Psychiatric Publishing.

Bajracharya, P., Summers, L., Amatya, A. K., \& DeBlieck, C. (2016). Implementation of a depression screening protocol and tools to improve screening for depression in patients with diabetes in the primary care setting. Journal for Nurse Practitioners, 12(10), 690-696. https://doi.org/10.1016/j.nurpra.2016.08.009

Bolin, J. N., Bellamy, G. R., Ferdinand, A. O., Vuong, A. M., Kash, B. A., Schulze, A., \& Helduser, J. W. (2015). Rural healthy people 2020: New decade, same challenges. The Journal of Rural Health, 31, 326-333. https://doi.org/10.1111/jrh.12116

Camacho, F., Yao, N., \& Anderson, R. (2017). The effectiveness of Medicare wellness visits in accessing preventive screening. Journal of Primary Care \& Community Health, 8(4), 247255. https://doi.org/10.1177/2150131917736613

Online Journal of Rural Nursing and Health Care, 20(1) http://dx.doi.org/10.14574/ojrnhc.v20i1.602 
Centers for Medicare and Medicaid Services. (2018a). Medicare shared savings program quality measure benchmarks for the 2019 performance year. Retrieved from https://www.cms.gov/Medicare/Medicare-Fee-for-Service-Payment/sharedsavingsprogram/ Downloads/2019-quality-benchmarks-guidance.pdf

Centers for Medicare and Medicaid Services. (2018b). Your Medicare coverage yearly wellness visits. Retrieved from https://www.medicare.gov/coverage/yearly-wellness-visits

Centers for Medicare \& Medicaid Services. (2019c). Medicare shared savings program. Retrieved from https://www.cms.gov/Medicare/Medicare-Fee-for-Service-Payment/sharedsavings program/index.html

Cronk, B. C. (2018). How to use SPSS: A step by step guide to analysis and interpretations (10th ed.). NY: Routledge.

Dallas Fort Worth Hospital Council Foundation. (2018). Healthy North Texas dashboard. Retrieved from http://www.healthyntexas.org/index.php?module=indicators\&controlle $\underline{\mathrm{r}=\text { index\&action }=\text { dashboard } \& \mathrm{id}=83016616388425148 \& \text { card }=0 \& \text { localeId }=2690}$

Doherty, J. A., Crelia, S. J., Smith, M. W., Rosenblum, S. F., Rumsey, E. M., Mabry-Hernandez, I. R., \& Ngo-Metzger, Q. (2018). Large health systems' prevention guideline implementation: A qualitative study. American Journal of Preventive Medicine, 54(1S1), S88-S94. https://doi.org/10.1016/j.amepre.2017.07.025

Donabedian, A. (2005). Evaluating the quality of medical care. The Milbank Quarterly, 83(4), 691-729. https://doi.org/10.1111/j.1468-0009.2005. 00397.x

Egger, J. R., Stankevitz, K., Korom, R., Angwenyi, P., Sullivan, B., Wang, J....Gross, J. (2017). Evaluating the effects of organizational and educational interventions on adherence to 
clinical practice guidelines in a low-resource primary-care setting in Kenya. Health Policy and Planning, 32, 761-768. https://doi.org/10.1093/heapol/czx004

Fawcett, J., \& Foust, J. B. (2017). Optimal aging: A Neuman systems model perspective. Nursing Science Quarterly, 30(3), 269-276. https://doi.org/10.1177/0894318417708413

Gorbenko, K., Metcalf, S. A., Mazumdar, M., \& Crump, C. (2017). Annual physical examinations and wellness visits: Translating guidelines into practice. American Journal of Preventive Medicine, 52(6), 813-816. https://doi.org/10.1016/j.amepre.2016.12.005

The Johns Hopkins Hospital/Johns Hopkins University School of Nursing. (2017). Appendix A: PET management guide. Retrieved from https://www.mghpcs.org/EED/EBP/Assets/ documents/pdf/2017_Appendix\%20A_PET\%20Management\%20Guide.pdf

Kim, W. K., Shin, D., \& Song, W. O. (2015). Depression and its comorbid conditions more serious in women than in men in the United States. Journal of Women's Health, 24(12), 978-985. https://doi.org/10.1089/jwh.2014.4919

Kroenke, K., Spitzer, R. L., \& Williams, J. B. (2001). The PHQ-9: Validity of a brief depression severity measure. Journal of General Internal Medicine, 16(9), 606-613. https://doi.org/ $\underline{10.1046 / \mathrm{j} .1525-1497.2001 .016009606 . \mathrm{x}}$

Kurth, A. E., Krist, A. H., Borsky, A. E., Baumann, L. C., Curry, S. J., Davidson, K., ...W., Weinstein, R. (2018). U.S. Preventive Task Force methods to communicate and disseminate clinical preventive services recommendations. American Journal of Preventive Medicine, 54(1S1), S81-S87. https://doi.org/10.1016/j.amepre.2017.07.004 
Langley, G. L., Moen, R., Nolan, K. M., Nolan, T. W., Norman, C. L., \& Provost, L. P. (2009).

The improvement guide: A practical approach to enhancing organizational performance (2 ed.). San Francisco, CA: Jossey-Bass.

Lantz, P. A., Evans, W. D., Mead, H., Alvarez, C., \& Stewart, L. (2016). Knowledge of and attitudes toward evidence-based guidelines for and against clinical preventive services: Results from a national survey. The Milbank Quarterly, 94(1), 51-76. https://doi.org/10.1111/1468-0009.12181

Mabry-Hernandez, I. R., Curry, S. J., Phillips, W. R., Garcia, F. A., Davidson, K. W., Epling, J. W., Bierman, A. S. (2018). U.S. Preventive Services Task Force priorities for prevention research. American Journal of Preventive Medicine, 54(1S1), S95-S103. https://doi.org/10.1016/j.amepre.2017.08.014

Medicare Learning Network. (2018). Rural Health Center. Retrieved from https://www.cms.gov/ Outreach-and-Education/Medicare-Learning-Network-MLN/MLNProducts/Downloads $\underline{\text { RuralHlthClinfctsht.pdf }}$

Mental Health America. (2018). The state of mental health in America 2018. Retrieved from http://www.mentalhealthamerica.net/sites/default/files/2018\%20The $\% 20$ State $\% 20$ of $\% 20$ MH\%20in\%20America\%20-\%20FINAL.pdf

Montana Geriatric Education Center. (2014). Screening for depression in older adults. Retrieved from http://health.umt.edu/Research\%20and\%200utreach/MTGEC/ScreeningforDepress ion2012.pdf

Moriarty, A. S., Res, M., Gilbody, S., McMillian, D., \& Manea, L. (2015). Screening and case finding for major depressive disorder using the Patient Health Questionnaire (PHQ-9): A 
meta-analysis. General Hospital Psychiatry, 37(6), 567-576. https://doi.org/10.1016/ j.genhosppsych.2015.06.012

National Alliance on Mental Health. (2018). Mental health by the numbers. Retrieved from https://www.nami.org/Learn-More/Mental-Health-By-the-Numbers

National Rural Health Association. (2019). About rural health care. Retrieved from https://www.ruralhealthweb.org/about-nrha/about-rural-health-care

Neuman Systems Model, Inc. (2005). The Neuman systems model of nursing. Retrieved from https://www.neumansystemsmodel.org/

Patient Health Questionnaire (PHQ) Screeners. (1999). Patient health questionnaire 9. Retrieved from https://www.integration.samhsa.gov/images/res/PHQ\%20-\%20Questions.pdf

Picardi, A., Lega, I., Tarsitani, L., Caredda, M., Matteucci, G., Zerella, M....Biondi, M. (2016). A randomised controlled trial of the effectiveness of a program for early detection and treatment of depression in primary care. Journal of Affective Disorders, 198, 96-101. https://doi.org/10.1016/j.jad.2016.03.025

Polit, D. F., \& Beck, C. T. (2017). Nursing research: Generating and assessing evidence for nursing practice (10th ed). Philadelphia, PA: Lippincott Williams \& Wilkins.

Pruchno, R. A., Wilson-Genderson, M., \& Heid, A. R. (2016). Multiple chronic condition combinations and depression in community-dwelling older adults. Journals of Gerontology Series A: Biological Sciences \& Medical Sciences, 71(7), 910-915. https://doi.org/10.1093/gerona/glw025 
Ratcliffe, M., Burd, C., Holder, K., \& Fields, A. (2016). Defining rural at the U.S. Census Bureau. Retrieved from https://www.census.gov/content/dam/Census/library/publications/2016/ acs/acsgeo-1.pdf

Schaffer, M. A., Sandau, K. E., \& Diedrick, L. (2013). Evidence-based practice models for organizational change: Overview and practical applications. Journal of Advanced Nursing, 69(5), 1197-1209. https://doi.org/10.1111/j.1365-2648.2012.06122.x

Spitzer, R. L., Kroenke, K., \& Williams, J. B. (1999). Validation and utility of a self-report version of PRIME-MD: the PHQ primary care study. Journal of the American Medical Association, 282(18), 1737-1744. https://doi.org/10.1001/jama.282.18.1737

Texas Department of Agriculture. (2016). County designations. Retrieved from https://www.texasagriculture.gov/Portals/0/forms/ER/Rural-Metro\%20Counties.pdf

Trangle, M., Gursky, J., Haight, R., Hardwig, J., Hinnenkamp, T., Kessler, D.... Myszkowski, M. (2016). Institute for clinical systems improvement: Health care guideline depression in primary care. Retrieved from https://www.icsi.org/wp-content/uploads/2019/01/Depr.pdf

University of Wisconsin Population Health Institute. (2018). Texas 2018 county health rankings report. Retrieved from https://www.countyhealthrankings.org/reports/state-reports/2020texas-report

United States Department of Health and Human Services. (2018a). Health professional shortage areas. Retrieved from https://data.hrsa.gov/tools/shortage-area/hpsa-find

United States Department of Health and Human Services. (2018b). Medically underserved area find. Retrieved from https://data.hrsa.gov/tools/shortage-area/mua-find 
U.S. Preventative Services Task Force. (2016). Final recommendation statement: Depression in adults: Screening. Retrieved from https://guidelines.gov/summaries/summary/49978/finalrecommendation-statement-depression-in-adults-screening? $\mathrm{q}=+++$ depression + screening

U.S. Preventive Services Task Force. (2019). Recommendations for primary care practice. Retrieved from https://www.uspreventiveservicestaskforce.org/uspstf/recommendationtopics?c=wlyhe

Whetsell, M. V., Gonzalez, Y. M., \& Moreno-Furgusson, M. E. (2015). Models and theories focused on a systems approach. In J. B. Butts \& K. L. Rich (Eds.), Philosophies and theories for advanced nursing practice. (2 ed., pp. 407-434). Burlington, MA: Jones \& Bartlett. 